\title{
Never Married
}

National Cancer Institute

\section{Source}

National Cancer Institute. Never Married. NCI Thesaurus. Code C51774.

Indicates a person who has never been married or whose marriages have been annulled. 